\title{
Prion diseases in humans: an update
}

ROB BUTLER

\begin{abstract}
Summary The year 2006 marks 20 years from the first identified bovine spongiform encephalitis in cows and 10 years from the first description of variant Creutzfeldt - Jakob disease in humans. The threatened epidemic in humans now appears unlikely, but psychiatrists need to be aware of recent developments in prion diseases.
\end{abstract}

\section{Declaration of interest None.}

When the mass incineration of British cattle was a recent memory 5 years ago, cases of variant Creutzfeldt-Jakob disease (vCJD) were increasing each year and educating doctors about the disease was a priority. I co-reviewed the psychiatric management of CJD for Advances in Psychiatric Treatment (Butler \& Fleminger, 2001). There were dire predictions about the impact of prion diseases on human health, but what has happened since? What is the latest research? And what is the relevance of prion diseases for psychiatrists in the coming years?

\section{THE THREATENED EPIDEMIC}

From the first death in 1995 until the end of 2005, 153 people died from vCJD in the UK (http://www.cjd.ed.ac.uk). There have been about 18 cases of vCJD in France and 12 in the rest of the world. The families and loved ones of those who died have had to contend not only with the disease itself but with healthcare systems that were unprepared, often ignorant and unable to provide a coordinated response. Some of the families formed themselves into support groups such as the CJD Support Network and the Human BSE Foundation. They have lobbied for better services, greater awareness from health professionals and easier access to potential treatments. A trust has been established to pay compensation to the victims of vCJD and their families (http:// www.cjdtrust.co.uk).

The number of deaths from vCJD in the UK appeared to peak in 2000 when 28 people died. Last year 5 people died. These numbers are surprisingly low in view of the millions of people who were exposed to infected beef products in the late 1980s. The transmission barrier may have been sufficient to prevent the feared epidemic. Deaths from sporadic CJD continue worldwide at about one per million people per year.

There have been some worrying developments. Cases have been identified in a number of countries around the world, and it is likely that people in more countries will be affected. Many were resident in the UK at some period, but others were probably exposed in their own country to indigenous bovine spongiform encephalitis (BSE) or imports from the UK.

There has been human to human transmission of vCJD via blood products. This comes with many ethical considerations, such as how to deal with those who were exposed to these blood products (Bird, 2004). There remains the risk of transmission by dura mater grafts, human pituitary hormones or surgical instruments because traditional sterilisation does not neutralise prions. Prion diseases are widespread in animals around the world, including scrapie in sheep, and are under-tested in some countries. Despite this, BSE has been detected in most European countries, USA, Canada and Japan.

\section{SPORADIC, INHERITED OR TRANSMITTED}

Prion diseases are associated with an abnormal, protease-resistant form of prion protein known as scrapie prion protein (Prusiner \& Hsiao, 1994). The function of prion protein is poorly understood. Some animals genetically engineered to lack the protein appear normal. Attempts to breed a prion protein-free cow are proving time consuming and costly.

The change in prion protein may occur in three different ways (Cohen et al, 1994). In sporadic prion disease, prion protein changes to the insoluble form spontaneously. Sporadic CJD accounts for most cases of CJD. In familial vCJD, an abnormality in the gene coding for prion protein produces a protein that is unstable and changes into the abnormal protein. It was the search for the transmissible agent for diseases such as kuru that led Prusiner (1982) to coin the term prion which stands for proteinaceous infectious agent. Prion diseases can be experimentally transmitted by directly inoculating the brain with the abnormal protein. This is the quickest and most reliable route, although incubation takes months and occasionally years. Transmission by eating is generally more difficult, but kuru was maintained through cannibalistic rituals. The incubation time for kuru can exceed 40 years.

\section{CLINICAL FEATURES AND INVESTIGATIONS}

Sporadic CJD peaks in incidence at between 50 and 70 years of age. It is a rapidly progressive dementia, often with severe cerebellar and extrapyramidal signs and myoclonus, causing death usually within a few months (Will \& Matthews, 1984). Psychiatric symptoms occur early in the disease in about a third of cases.

Variant CJD differs from sporadic CJD in a number of ways (Will et al, 1996); the National CJD Surveillance Unit published the clinical features of the first 100 cases of vCJD (Spencer et al, 2002). Onset is usually at a young age, mean 26 years, range 12 to 74 years. Patients tend to present to psychiatrists as first-line specialists, with early symptoms of dysphoria, withdrawal, anxiety, irritability, insomnia or loss of interest. Neurological symptoms occur on average 2 months later. These include pain, headaches, dropping things, sweatiness and loss of consciousness. The combination of a psychiatric disorder with affective or psychotic features, and persistent pain, dysarthria, gait ataxia, or sensory symptoms, should raise the suspicion of vCJD, particularly if there is a suggestion of cognitive impairment. Mean survival is a little over 1 year. 
A number of investigations are useful. Electroencephalograms often show periodic synchronous discharges in CJD that are usually absent in vCJD. Computed tomography is usually normal or shows only atrophy. Magnetic resonance imaging may show a high signal in the posterior thalamus (pulvinar) in vCJD. In sporadic CJD, cerebrospinal fluid is usually positive for the brain protein 14-3-3 (which may be a marker for neuronal damage), but this test is not useful for vCJD. Tonsillar biopsy is used for diagnosing vCJD.

Most cases of sporadic CJD, and until recently all cases of $\mathrm{vCJD}$, have been homozygous for methionine at codon 129 of the prion protein gene (the MM genotype found in around $40 \%$ of the general population). The announcement in 2004, that someone with vCJD infection (but not the illness) linked to a blood transfusion had the MV genotype (found in $50 \%$ of the general population) suggests this wider group of people may be at risk, perhaps with different incubation characteristics.

\section{WHAT TO DO IF YOU SUSPECT A PRION DISEASE}

A number of countries have established surveillance centres to monitor the occurrence of prion diseases. In the UK, psychiatrists who suspect that a patient has CJD should make a referral to the local neurological service which should contact the National CJD Surveillance Unit in Edinburgh. Their website (http:// www.cjd.ed.ac.uk) includes information about managing CJD and addresses of support organisations. In the USA, doctors

ROB BUTLER, MRCPsych, Redwald Unit, St Clement's Hospital, Foxhall Road, lpswich, Suffolk IP3 8LS, UK. Email: robbutlerl00@hotmail.com

(First received I2 January 2006, final revision II May 2006, accepted 2 June 2006)

should contact the National Prion Disease Pathology Surveillance Center (http:// www.cjdsurveillance.com).

It has been difficult to find treatments. In 2004, the Medical Research Council in the UK launched the PRION-1 trial that focuses initially on quinacrine, an antimalarial that clears scrapie prion protein in cell culture. Pentosan polysulphate has shown promising results in animals. It has to be delivered directly to the brain. In a high-profile case, a father won a court battle to have pentosan polysulphate made available for his son. Attempts to find a vaccine for the abnormal prion protein are still at an early stage. A better understanding of the mechanism of disease is offering novel treatment approaches, such as finding agents that directly target prion protein. For example, transgenes have reversed prion disease in mice by deleting prion protein genes (Mallucci \& Collinge, 2004).

\section{CONCLUSIONS}

Most of what we wrote in Advances in Psychiatric Treatment is still relevant 5 years on, but prion diseases are better understood. Almost two-thirds of people with vCJD will see a psychiatrist at some stage of their illness (Spencer et al, 2002).

Psychiatrists need to know about prion diseases; they need to complete good clinical assessments, particularly in unusual cases; and they need to be responsive to this group of patients and their families. Fortunately, the worst predictions have not materialised, but it is too early to lower our awareness of this group of disorders.

\section{REFERENCES}

Bird, S. M. (2004) Recipients of blood or blood products "at vCJD risk". BMJ, 328, $118-119$.

Butler, R. \& Fleminger, S. (200I) Creutzfeldt- Jakob disease and its implications for psychiatric management. Advances in Psychiatric Treatment, 7, 50-56.

Cohen, F. E., Pan, K. M., Huang, Z., et al (1994) Structural clues to prion replication. Science, $\mathbf{2 6 4}$, 530-531.

Mallucci, G. \& Collinge, J. (2004) Update on Creutzfeldt- Jakob disease. Current Opinion in Neurology, 17, 641-647.

Prusiner, S. B. (1982) Novel proteinaceous infectious particles cause scrapie. Science, 216, 136-144.

Prusiner, S. B. \& Hsiao, K. K. (1994) Human prion diseases. Annals of Neurology, 35, 385-395.

Spencer, M. D., Knight, R. S. G. \& Will, R. G. (2002) First hundred cases of variant Creutzfeldt - Jakob disease: retrospective case note review of early psychiatric and neurological features. BMJ, 324, 1479-1482.

Will, R. G. \& Matthews, W. B. (1984) A retrospective study of Creutzfeldt- Jakob disease in England and Wales 1970-79. I. Clinical features. Journal of Neurology, Neurosurgery and Psychiatry, 47, 134-140.

Will, R. G., Ironside, J.W., Zeilder, M., et al (1996) A new variant of Creutzfeldt- Jakob disease in the UK. Lancet, 347, 921-925. 